\title{
The effect of self-care educational program on quality of life of elderly people in Ahvaz, Iran
}

\author{
Shahram Baraz ${ }^{1}$, Maryam Rostami ${ }^{2}$, Abdolazim Tavakholi Vardanjani ${ }^{3}$, Reza masoudi ${ }^{4}$, Leili Rabiei ${ }^{5}$, Safar Ali Esmaeili \\ Vardanjani6* \\ ${ }^{1}$ Doctoral Candidate, School of Nursing and Midwifery, Ahvaz Jundishapur University of medical sciences, Ahvaz, Iran. \\ ${ }^{2}$ Doctoral Candidate, School of Nursing and Midwifery, Islamic Azad University of Masjed Solaiman, ahvaz,Iran. \\ ${ }^{3}$ MSc Student in Intensive Care Nursing, Tehran University of Medical Science, Tehran, Iran. \\ ${ }^{4}$ Doctoral Candidate, School of Nursing and Midwifery, Ahvaz Jundishapur University of medical sciences,Ahvaz, Iran. \\ ${ }^{5}$ M.Sc. Student, Department of Health Education and Health Promotion, School of Health, Isfahan University of Medical Sciences, Isfahan, Iran. \\ ${ }^{6}$ Ms in Nursing Education, Shahrekord University of Medical Science, Shahrekord, Iran \\ safaraliesmaili@yahoo.com*
}

\begin{abstract}
The aim of this study was to determine the effect of self-care educational program on quality of life of the elderly in Ahvaz, Iran, in 2010. In this pre- test/post-test intervention study design, 349 elderly men and women aged 65 and older were included, using each subject as her/his own control. The educational program was introduced to participants by trained research assistants through six 40-minute sessions over a period of four months. Quality of life by using Short Form Health Survey was assessed before and after the educational sessions. The paired $t$-test was used to compare the total and subscale mean scores of the Quality of life before and after the training. Physical component summary and mental component summary scores increased after implementing the educational program; $(p<0.001)$. Such statistically significant increase was seen in all eight subscale mean $( \pm \mathrm{SD})$ scores of the Quality of life. Applying the educational program has a significant effect on the Quality of life in the elderly.
\end{abstract}

Keywords: Quality of life, Elderly, Iran, Self-care

\section{Introduction}

Since the 1950s, population of the elderly in Iran has greatly increased (Sheikholeslami et al., 2012). According to the United Nations (UN), there were 4,562,000 people aged 60 and above in Iran in 2006, which was $6 \%$ of the total population. It is estimated that $21.7 \%$ of the Iranian population will be aged 60 and above by 2050 (Heydari et al., 2012; Kun., 2001). Thus it is vital to anticipate requirements of this age group in Iran and to plan appropriate policies to address their growing needs and to support their quality of life (QOL) (Tajvar et al., 2008).

The elderly are very respectful in Islam and receive their own families' care and emotional and psychosocial supports. Several verses in Holy Quran consider the elderly as valuable people for society and ask the Muslims to respect them (Holy Quran; Asra surah; verse 23). Moreover, there are many parts in the Persian literature and poems regarding the valuable position of the elderly in society and family. Family members consider the elderly as valuable and important individuals and meet their needs (Mellor, 2008; Gureje et al., 2006). However, authorities and politicians, unfortunately, do not pay much attention to the elderly and abdicate the task of caring for them to their families; they believed that the families are able to meet the elderly needs completely. However, the abundance of the problems and disabilities associated with aging produce many socio-economic and healthcare problems for the families with elderly members that have negative effects on their QOL (Masoudi et al., 2012; www. Census.gov/population).

In Iran, the elderly health status and their ability to meet their own healthcare needs decrease with the aging process. This is because that many elderly lose their financial independence and become financially dependent to others. In other words, with the annual increase of healthcare costs, the elderly ability to pay for their medical treatments and procedures decreases. This is particularly important for the uninsured elderly (Tajvar et al., 2008; Sheykhi, 2004). A study showed that 25 to $30 \%$ of the Iranian elderly are not under insurance coverage (Gureje et al., 2006).

Investigations show that in Iran only one percent of all the national approved laws and regulations are related to the elderly population, from which 62 percent are economic, 22 percent are social, and 16 percent are healthcare-related ones. However, healthcare services in Iran are not commensurate with the elderly needs. Moreover, expensiveness of the alternative home-based caring services and scarcity of them in the small cities, in addition to the reluctance of the families to transfer their elderly to the caring homes, make the caring for them as a challenging healthcare issue (Shojaie and Nejati, 2008). 
The progressive elderly population growth is an important factor affecting the socio-economic and healthcare systems (Akbulut et al., 2008). with increasing age; the elderly become more susceptible to various medical and psychiatric disorders. Therefore, it is essential to increase care and consider an effective care program for the elderly (Donmez et al., 2005; Gale., 2011; Rao, 2000). All the above-mentioned factors can decrease health-related QOL (Matsuo et al., 2003).

Studies emphasized that with aging, the elderly medical expenses increase progressively (Jenson, 2007; Dausch, 2003). The reasons are frequent drug consumption, more use of healthcare services, prolongation of the elderly use of healthcare facilities because of the frequent and prolonged hospitalizations, and expensiveness of medicinal and medical costs.

The elderly constitute about $50 \%$ of hospitalized patients, $85 \%$ of patients hospitalized in the chronic care units, $90 \%$ of elderly home residents, $48 \%$ of patients hospitalized in the intensive care units, and $60 \%$ of all cancer patients. Moreover, $70 \%$ of all hospital services are for the elderly (Askarizade et al., 2008; Shojaie and Nejati, 2008).

Therefore, caring for the elderly coerces the healthcare policy-makers to use educational and caring models to meet their healthcare needs and to alleviate the healthcare expenses. Health is the most important factor determining the QOL of the elderly, and as age increases, health decreases (Chan, 1998). As life expectancy increases, it is simultaneously necessary to improve both the social and mental conditions as well as the QOL of humans (Matsuo, 2003).

Herbert and Brayne reported that there is a negative correlation between the inability of the elderly to perform daily activities and their cognitive achievements (Hébert et al., 1999).

Studies indicated that one-fifth of people incapable of performing their daily activities needed physical support. This figure constituted about $58 \%$ of people who were above 65 years of age (Hellström et al., 2004). The elderly who need support from others to perform their daily activities have poor QOL (Lawes, 2003; Paluska and Schwenk, 2000; Fassino et al., 2002; Tamiya et al., 2001). Because of a rapid increase in the elderly population and their specific needs, it is necessary to study the QOL of this group and to work on simple and cost-beneficial programs that can improve their QOL.

The elderly need to engage in activities that improve their health condition and QOL. Orem (the developer of the self-care theory) referred to these activities as "self-care agency" (Orem, 1995). "Self-care agency" is the core of the Orem's self-care theory. Based on the Orem's theory, self-care is a learned activity that can fulfill the global, developmental and health deviation needs. Selfcare includes activities that help the people to maintain or improve their health status, focused attention, controlled use of energy, knowledge acquisition and developing a repertoire of skills. The elderly process and its problems may affect the individuals' self-care ability, optimum use of energy, ability to obtain information regarding diseases and their managements, and strategies used for managing their lives. Self-care agency in the elderly is poorly developed to enable them to manage and control their age-related problems. Self-care agency deficiency may negatively affect the elderly quality of life. Nursing activities focus on the self-care deficiency. Educating the elderly in addition to the implementation of a caring program designed based on the elderly abilities can enhance their self-care agency and prevent its wastage. In such a way, the elderly can assume the responsibility of caring for themselves (Smolen and Topp, 2001).

The more information the elderly have, the more positive role they will play in their self-care activities. Nurses play an important role in educating the elderly to cope with their limitations, evaluating their health status, and following-up the implementation of the educated materials. Along with the elderly knowledge development, their decision-making and functional abilities and coping mechanisms also improve. Therefore, the aim of education is to help the elderly to assume more self-care responsibility. In Iran, the Orem's self-care theory has been tested many times in patients undergoing hem dialysis (Baraz et al., 2010), and patients with multiple sclerosis (Hamidizadeh et al., 2009), and diabetes mellitus (Bagheri et al., 2008); however, the efficacy and usefulness of the theory in the elderly population have remained unknown.

Therefore, with an educational intervention program, we tried to improve the level of health-related QOL of the elderly in Ahvaz, Iran. This study was carried out to investigate the effects of the self-care program on the QOL of the elderly who were treated at health centers of Ahvaz, Iran, during 2009 and 2010. 


\section{Methods}

\subsection{Design}

This study was a pre- test/post-test intervention study design, using each subject as her/his own control.

\subsection{The Sample}

The required number of participants for our study was computed using

$$
n=\frac{\left(z_{1-\alpha}+z_{1-\beta}\right)^{2} \times \sigma_{\bar{d}}^{2}}{\bar{d}^{2}}
$$

(Kirkwood and Sterne, 2003), to detect a mean change of at least 5 units on the SF-36

score after educational intervention $(\bar{d}=5)$. For $\alpha=\beta=0.05$ and $\sigma_{\bar{d}}^{2}=625$, the sample size was computed as 325 . It was anticipated that $5 \%$ of the sample would be lost from the initial recruitment to the final intervention; therefore it was necessary to recruit 350 patients to achieve an adequate sample size. In total, 349 (about 6\%) elderly (aged $\geq 65$ ) who met the eligibility criteria were selected. The researchers introduced themselves to the managers of health centers in Ahvaz. They explained the purposes of the study to all the participants. The criteria for selecting participants were (a) a minimum age of 65, (b) having no mental disease, (c) living in Ahvaz and (d) a desire to participate. Having heart, lung, metabolic, muscular, and musculoskeletal diseases were criteria for excluding individuals.

\section{Quality of Life (QOL)}

For measuring QOL, Iranian version of the Short Form Health Survey (SF-36) was used. This instrument has been widely utilized among patients suffering from various diseases as well as the elderly in both Iran and other countries (Ware et al., 1994; Beddhu et al., 2000; Gitlin et al., 2006; Ware et al., 2000). This scale contains 36 items and is divided into eight subscales that assess general health (GH): physical function (PF) health problems resulting in limitations of physical activities; physical role (PR), physical disability resulting in limitations of usual role activities; body pain (BP), daily activities influenced by pain; general health (GH), self-perception of overall health; vitality (VT), overall energy level or lack thereof; emotional role (ER), emotional problems resulting in limitations of usual role activities; mental health (MH), psychological wellbeing and stress; and social function (SF), physical and emotional problems resulting in limitations of social activities. The physical and mental components of the eight subscales were combined into physical component summary (PCS) and mental component summary (MCS) scores. The PCS measure is primarily comprised of the physical functioning, role functioning - physical and bodily pain scales. The MCS is primarily comprised of the mental health, role functioning - emotional and social functioning scales. Two of the scales (vitality and general health) contribute to both component summaries. The score of each subscale ranges from 0 to 100 . Higher scores on the SF-36 scales and component summaries indicate better physical and mental functioning and freedom from pain (Ware et al., 2000).

\section{Validity}

The validity of the Persian translation of SF-36 has been approved in former studies (Montazeri et al., 2005; Ware et al., 1993).

\section{Reliability}

The Cronbach alpha was calculated to investigate the internal consistency of the SF-36 questions. The alpha obtained was 0.85 , which is an appropriate reliability index.

\section{Ethics}

The study protocol was approved by the Ethics Committee of the Nursing College of Jundishapur Medical Science University, Ahvaz, Iran. All participants were required to sign consent forms. They were also told that the information obtained would be kept confidential.

\section{Educational intervention}

The participants received a 4-month QOL educational program. The main contents of this program measured factors that affect QOL, including how to structure an appropriate dietary regimen, types of foods eaten, limitation of salt intake, weight adjustment, medications prescribed, regulating medications' consumption time, physical activities (such as walking, climbing the stairs, and using auxiliary devices), giving up dangerous habits (such as smoking), applying self-care techniques, and controlling the factors 
influencing health.

The program consisted of theoretical and practical parts such as lectures, slide presentations, and practical demonstrations. These were taught in sixteen 40-minute sessions over a 4-month period by research assistants. The research assistants were trained under supervision of the authors a month before the study, and performed the program similarly in all health centers in Ahvaz, Iran.

\section{Statistical Analyses}

Descriptive indices such as frequency, percentage, mean, and standard deviation (SD) were used to present data. A paired $t$-test was used to compare the SF-36 scores before and after the educational program. All analyses were carried out using SPSS software for Windows (Ver. 16.0).

\section{Results}

A total of 349 participants (169 males and 180 females) were enrolled. Mean (SD) age of the participants was 74.51 (6.81) years (range, 65-92). Demographic characteristics and smoking habits of the participants are presented in Table 1. About half of the participants (169 individuals, 48.6\%) were illiterate, and most (241 subjects, 69.1\%) were married (241 individuals, 69.07\%) and were nonsmokers (282 subjects, $80.8 \%$ ).

Comparisons of the overall mean score of SF-36 questionnaire and its eight subscales as well as PCS and MCS before and after the self-care educational courses are presented in Table 2. As shown, after the educational intervention there were statistically significant increase in mean scores in all subscales as well as total SF-36 score $(p<0.001)$.

\section{Discussion}

Owing to an increased life expectancy worldwide as well as a rapid increase in the population of the elderly, it is of great importance to improve QOL of the elderly. An active aging process is optimizing opportunities with regard to health, cooperation, and safety to improve the QOL for the elderly (Ware et al., 1994). Of course, QOL is an inseparable part of an active aging process. The overall mean score of QOL significantly increased after education in the current study. This finding shows that the self-care education implemented had significant impacts on the QOL of the studied elderly population. The results are in agreement with those of Salari, who studied the impacts of the counseling model of constant care on the QOL of the elderly in Zahedan, Iran. He reported that before the intervention, mean QOL score was 40.6 which increased to 65.5 following education (Montazeri et al., 2005). The results of the present study are also in line with the findings of Albokordi study, which investigated QOL in Shahinshar, Iran (Ware et al., 1993).

In spite of the consistency of the results of the studies carried out in Iran, mean QOL scores in other countries are significantly higher than those in Iran. For instance, Subasi and Hayran (2005), indicate that mean scores of physical functioning, physical role, general health, and emotional role were 84.6, 77.8, 70.6, and 90.6, respectively (Subasi and Hayran, 2005). All the scores of these subscales are higher than the current scores in Iran. It has been noted that people who have an active lifestyle have a better QOL, are less depressed, more satisfied, and more socially interactive than those with less active lifestyles.

QOL is influenced by many factors, including age, culture, and also co-morbidities, which cannot be altered by medical staff alone. There are other influential factors that also cannot be controlled by medical staff such as environmental, individual, and social conditions, physical activities, and nutrition. It is possible, however, to control such factors by giving the necessary information to the elderly and their family members (imparted by the nurses). The cooperation of the patient in the process of treatment and care is needed to control problems and to improve QOL. Therefore, raising the awareness and knowledge of the elderly regarding factors that affect QOL is required. Moreover, the QOL of the elderly in Khuzestan province, particularly Ahvaz, has not been investigated before. This was the reason why researchers attempted to investigate the impacts of the Orem self-care model on the QOL of the elderly in this region. Demura et al (2003) reported that the elderly who were capable of performing their daily activities were less likely to become depressed. They also pointed out that there was a significant correlation between daily activities and anxiety as well as depression. In the mentioned study, the elderly who were interviewed reported that physical activities, daily activities, having free time, watching TV, reading books and newspapers, walking, and living with other members of their family all affected their QOL (Demura et al., 2003; Tsai et al., 2004). The main outcomes of this study are the positive impact of the self-care education, the necessity of focusing on care issues, the use of models that can foster self-care, and controlling and adjusting the factors influencing QOL. Since the possible range of score of the SF-36 questions and also the QOL and its subscales are from 0 to 100, the mean of 50 with the SD of 15 might be considered as the basic normal index for our society. On the basis of the results of our study, mean scores of GH, BP, VT, and ER subscales of QOL before the study were significantly $(p<0.05)$ below the mean of 50 . However, other mean scores were not appreciably above 50 . This further justifies the necessity of performing more studies to improve the QOL of the elderly in Iran. 
Table 1. General characteristics of the participants in the self-care ducational intervention in Ahvaz, Iran, 2009-2010

\begin{tabular}{|c|c|c|}
\hline Characteristics & $\mathbf{N}$ & $\%$ \\
\hline \multicolumn{3}{|l|}{ Gender } \\
\hline Male & 169 & 48.4 \\
\hline Female & 180 & 51.6 \\
\hline \multicolumn{3}{|l|}{ Marital Status } \\
\hline Married & 241 & 69.07 \\
\hline Single & 8 & 2.29 \\
\hline Separated & 10 & 2.86 \\
\hline Widow & 90 & 25.78 \\
\hline \multicolumn{3}{|l|}{ Education level } \\
\hline Illiterate & 169 & 48.42 \\
\hline Primary School & 102 & 29.23 \\
\hline Secondary School & 54 & 15.47 \\
\hline High school diploma & 13 & 3.72 \\
\hline Higher than diploma & 10 & 2.86 \\
\hline \multicolumn{3}{|l|}{ Residency status } \\
\hline Sanatorium & 2 & 0.3 \\
\hline Home & 347 & 99.7 \\
\hline \multicolumn{3}{|l|}{ Occupation } \\
\hline Staff & 47 & 13.5 \\
\hline Worker & 40 & 11.5 \\
\hline Farmer & 25 & 7.2 \\
\hline Military & 15 & 4.3 \\
\hline At home & 140 & 40.1 \\
\hline Other & 82 & 23.4 \\
\hline \multicolumn{3}{|l|}{ Income source } \\
\hline Retirement salary & 101 & 29.2 \\
\hline Insurance & 64 & 18.5 \\
\hline Family & 72 & 20.8 \\
\hline No income & 90 & 25.7 \\
\hline Governmental charity & 20 & 5.8 \\
\hline \multicolumn{3}{|l|}{ Smoking habits } \\
\hline Non-smoker & 282 & 80.8 \\
\hline$<10$ & 7 & 2.2 \\
\hline $10-20$ & 25 & 7.3 \\
\hline$>20$ & 34 & 9.7 \\
\hline
\end{tabular}

The authors believe that the most important and necessary requirements for the QOL of the Iranian elderly relate to family and social issues. Therefore, programs targeting requirements such as rehabilitation centers, financial support systems, social security, treatment insurance, etc. should be implemented accordingly by governmental organizations. Also, family environment problems for those who 
live with their families should be solved through appropriate educational programs for family members. Periodic programs should be carried out for nursing home workers to reinforce the need for an increase in the level of providing care and QOL for the elderly.

A limitation of this study was that relatively healthy subjects were included, and therefore the results may not be generalized to the elderly with co-morbidities.

Applying the self-care educational program yielded satisfactory results regarding QOL using SF-36 in a group of healthy elderly aged 65 or more in Ahvaz, Iran.

Table 2. Mean $( \pm S D)$ scorers of SF-36 and its subscales in the studied population before and after self-care educational intervention in Ahvaz, Iran, 2008-2009.

\begin{tabular}{||l||l||l|l||}
\hline \multicolumn{1}{|c|}{ Subscales } & \multicolumn{1}{|c|}{$\begin{array}{c}\text { Before } \\
\text { Mean }( \pm \text { SD })\end{array}$} & $\begin{array}{c}\text { After } \\
\text { Mean }( \pm \text { SD })\end{array}$ & p-value \\
\hline \hline General health & $38.71( \pm 16.5)$ & $47.81( \pm 17.58)$ & $<0.001$ \\
\hline Physical role & $56.9( \pm 17.31)$ & $65.17( \pm 16.95)$ & $<0.001$ \\
\hline Physical functioning & $49.02( \pm 26.31)$ & $58.08( \pm 31.09)$ & $<0.001$ \\
\hline Mental health & $54.92( \pm 18.48)$ & $68.34( \pm 19.29)$ & $<0.001$ \\
\hline Social functioning & $58.1( \pm 18.27)$ & $67.90( \pm 41.05)$ & $<0.001$ \\
\hline Body pain & $50.93( \pm 20.79)$ & $56.35( \pm 20.87)$ & $<0.001$ \\
\hline energy & $\begin{array}{l}49.756 \\
( \pm 14.30)\end{array}$ & $61.73( \pm 16.36)$ & $<0.001$ \\
\hline Emotional role & $53.90( \pm 17.58)$ & $64.21( \pm 17.42)$ & $<0.001$ \\
\hline $\begin{array}{l}\text { Physical Component Summary } \\
\text { (PCS) }\end{array}$ & $49.10(14.82)$ & $57.75(15.17)$ & $<0.001$ \\
\hline $\begin{array}{l}\text { Mental Component Summary } \\
\text { (MCS) }\end{array}$ & $51.09(12.88)$ & $61.87(15.07)$ & $<0.001$ \\
\hline
\end{tabular}

\section{Acknowledgement}

The authors would like to thank the Dean School of Nursing and Midwifery, Ahvaz Jundishapur University of medical sciences and all the elderly in the healthcare centers of Ahvaz (Iran) who participated in this study. We also thank the, Ahvaz Jundishapur University of medical sciences for its financial support of this study.

\section{Conflict of interest: No conflict of interest has been declared by the authors.}

\section{References}

1 Sheikholeslami F, Masole SR, Rafati P, Esmaeili Vardanjani SA, Yazdani Talami MR and Khodadadi N (2012) The relationship between the religious beliefs and the feeling of loneliness in elderly. Indian J. Sci. Technol. 5(3), 2411-2416.

2- Heydari J, Khani S and Shahhosseini Z (2012) Health-related quality of life of elderly living in nursing home and homes in a district of Iran: Implications for policy makers. Indian J. Sci. Technol. 5(5), 2782-2787.

3. Kun LG (2001) Tele health and the global health network in the 21 st century. From home care to public health informatics. Comput. Methods Programs Biomed. 64,155-167.

4- Tajvar M, Arab M and Montazeri A (2008) Determinants of health-related quality of life in elderly in Tehran,Iran. BMC Public Health. 8, 323 .

5• Mellor D, Russo S, McCabe MP, Davison TE and George K (2008) Depression training program for caregivers of elderly care recipients: Implementation and qualitative evaluation. J. Gerontol. Nurs. 34, 8-15.

6• Gureje O, Ogunniyi A, Kola L, Afolabi E (2006) Functional disability in elderly Nigerians: Results from the Ibadan study of 
aging. J. Am. Geriatr. Soc. 54(11),1784-1789.

7 Masoudi R, Esmaeili Vardanjani S.A, Rabiei L, Moghadassi J,Khayri F and Rahimi M. A group-foundation exercise schedule on quality c life and well-being in older men and women. Indian J. Sci. Technol. 5(2), 2165-2169.

8- Barnes JS and bennet FC (2000) The Asian population: census 2000.brief, C2KBR/16-01, US. Census Bureau, Washington DC at: http://www. Census.gov/population.

9• Sheykhi MT (2004) Elderly people living in nursing homes in Iran. Afr. Asian Studies. 3,103-118.

10 Shojaie F and Nejati V (2008) Elderly- caring service pattern in USA comparing with IRAN. Salmand; 3, 66-75 [Persian].

11 Akbulut GC and Ersoy G (2008) Assessment of nutrition and life quality scores of individuals aged 65 and over from different socio-economic levels in Turkey. Arch. Gerontol.Geriat. 47, 241-252.

12• Donmez L, Gokkoca Z and Dedeoglu N (2005) Disability and its effects on quality of life among older people living in Antalya city center, Turkey. Arch. Gerontol. Geriatr. 40, 213-223.

13. Gale CR, Sayer AA, Cooper C, et al. (2011) Factors associated with symptoms of anxiety and depression in five cohorts of community-based older people: the HALCyon (Healthy Ageing across the Life Course) Programme. Psychol. Med. $24,1-17$.

14 - Rao R (2000) Cerebrovascular disease and late life depression: an age old association revisited. Int. J. Geriatr. Psychiatry. 15, 419-33.

15. Matsuo M, Nagasawa J, Yoshino A, Hiramatsu K and Kurashiki K (2003) Effects of activity participation of the elderly on quality of life. Yonago Acta Medica. 46, 17-24.

16• Jenson J (2007) Health care spending and aging of the population. CRS report for congress, Order code: RS22619.

17• Dausch JG (2003) Aging issues moving mainstream. J. Am. Diet. Assos. 103, 683-684.

18 Askarizade M, Arab M, Mohammadalizade S, et al. (2008) Staff nurses knowledge of aging process and their attitude toward elder people. Iran J.Nursing. 21, 19-27 [Persian]

19. Chan KM, Pang WS, Ee CH, Ding YY and Choo P (1998) Self-perception of health among elderly community dwellers in Singapore. Ann. Acad. Med. Singapore. 27, 461-467.

20 Hébert R, Brayne C and Spiegelhalter D. (1999) Factors associated with functional decline and improvement in a very elderly community-dwelling population. Am. J. Epidemiol. 150, 501-510.

21 Hellström Y, Persson G and Hallberg IR (2004) Quality of life and symptoms among older people living at home. J Adv Nurs. 48, 584-593.

22. Lawes D (2002) A retrospective review of emergency admission for head injury in the over 75s. Injury. 33, 349-351.

23• Paluska SA and Schwenk TL (2000) Physical Activity and Mental Health: current concepts. Sports Med. 29,167-180.

24- Fassino S, Leombruni P, Abbate Daga G, Brustolin A, Rovera GG, Fabris F (2002) Quality of life in dependent older adults living at home. Arch. Gerontol Geriatr. 35, 9-20.

25- Tamiya N, Kobayashi Y, Murakami S, et al. (2001) Factors related to home discharge of cerebrovascular disease patients: 1-year follow-up interview survey of caregivers of hospitalized patients in 53 acute care hospitals in Japan. Arch. Gerontol. Geriatr. 33,109121.

26• Orem D (1995) Nursing concepts of practice. New York; Louis: Mosby.

27 Smolen MD and Topp R (2001) Self-care agency and quality of life among adults diagnostic with inflammatory bowel disease. Qual. Life Res. 10, 379-387.

28 Baraz S, Parvardeh S, Mohammadi E, Broumand B (2010) Dietary and fluid compliance: an educational intervention for patients having haemodialysis. J. Adv. Nurs. 66(1), 60-68.

29• Hamidizadeh S, Masoudi R, Ahmadi F, Mohammadi E. Evaluation of the effect of self care program based on the OREM framework on the physical quality of life in multiple sclerosis patients. Journal of Shahid Sadoughi University of Medical Sciences and Health Services, 2009; 17: 20-29 [Persian].

30 Bagheri P, Zandi M, Vares Z, Masoudi A, Adib H. Self care situation in diabetic patients referring to Kashan Diabetic center, in 2005. FEYZ, 2008; 12(1 (SERIAL 45)):88-93 [Persian]. 
31 Kirkwood BR, Sterne JAC. Essentials of Medical Statistics. 2nd ed. Blackwell Publishing Ltd; 2003

32- Ware, J.E. Jr., M. Kosinski, and S.D. Keller. SF-36 Physical and Mental Summary Scales: A User's Manual. Boston, MA: The Health Institute, New England Medical Center; 1994.

33• Beddhu S, Bruns FJ, Saul M, Seddon P, Zeidel ML. A simple comorbidity scale predicts clinical outcomes and costs in dialysis patients. Am J Med. 2000 1; 108: 609-13

34- Gitlin LN, Winter L, Dennis MP, Corcoran M, Schinfeld S, Hauck WW. A randomized trial of a multicomponent home intervention to reduce functional difficulties in older adults. J Am Geriatr Soc 2006; 54: 809-16.

35• Ware J.E., Snow K.K., Kosinski M. \& Gandek B. SF-36 Health Survey Manual and Interpretation Guide. Quality Metric Incorporated, Lincoln.2000

36• Montazeri A, Goshtasebi A, Vahdaninia M, Gandek B. The Short Form Health Survey (SF-36): Translation and Validation Study of the Iranian Version. Qual Life Res, 2005; 14: 875-82.

37• Ware, J.E. Jr., K.K. Snow, M. Kosinski, and B. Gandek. SF-36 Health Survey Manual and Interpretation Guide. Boston, MA: The Health Institute, New England Medical Center. 1993.

38- Subasi F, Hayran O. Evaluation of life satisfaction index of the elderly people living in nursing homes. Archives of Gerontology and Geriatrics, 2005; 41: 23-29.

39- Demura S, Sato S. Relationships between depression, lifestyle and quality of life in the community dwelling elderly: a comparison between gender and age groups. J Physiol Anthropol Appl Human Sci. 2003 May;22(3):159-66

40 Tsai SY, Chi LY, Lee LS, Chou P. Health Related Quality of Life among Urban, Rural and Island Community Elderly in Taiwan. J Formos Med Assoc, 2004; 103: 196-204. 